\title{
Differences in photosynthetic capacity, chlorophyll fluorescence, and antioxidant system between invasive Alnus formosana and its native congener in response to different irradiance levels
}

\begin{tabular}{|r|l|}
\hline Journal: & Botany \\
\hline Manuscript ID & cjb-2016-0026.R1 \\
\hline Manuscript Type: & Article \\
\hline Date Submitted by the Author: & 13 -Jun-2016 \\
\hline Complete List of Authors: & $\begin{array}{l}\text { Liu, Shi-liang; Sichuan Agricultural University } \\
\text { Yang, Rong-jie; Sichuan Agricultural University } \\
\text { Ren, Bo; Sichuan Academy of Forestry } \\
\text { Wang, Mao-hua; Chungnam National University } \\
\text { Ma, Ming-dong; Sichuan Agricultural University }\end{array}$ \\
\hline Keyword: & $\begin{array}{l}\text { Invasiveness, Irradiance acclimation, Photoinhibition, Photosynthesis, } \\
\text { Plasticity }\end{array}$ \\
\hline &
\end{tabular}




\section{Differences in photosynthetic capacity, chlorophyll fluorescence, and antioxidant system between invasive Alnus formosana and its native congener in response to different irradiance levels}

Shi-liang Liu ${ }^{1}$, Rong-jie Yang ${ }^{1}$, Bo Ren ${ }^{2}$, Mao-hua Wang ${ }^{1,3}$, Ming-dong Ma ${ }^{1, *}$

1 College of Landscape Architecture, Sichuan Agricultural University, Chengdu, Sichuan 611130, P.R. China

2 Institute of Forestry Research, Sichuan Academy of Forestry (SAF), Chengdu, Sichuan 610081, P.R. China

3 College of Agriculture and Life Sciences, Chungnam National University, Daiden, Daejeon 305754, South Korea

*Corresponding author:

Ming-dong Ma (email: 610245498@qq.com, mmingdong1958@gmail.com) 


\begin{abstract}
We compared the invasive Alnus formosana with its native congener (A. cremastogyne) at three irradiances in terms of photosynthesis, chlorophyll fluorescence and antioxidant system. The increased light-saturated photosynthetic rate $\left(A_{\max }\right)$ and light saturation point (LSP) contributed directly to the increased performance of the invasive. The invasive species had also higher plasticity in carotenoid and total chlorophyll than the native species at $100 \%$ irradiance, potentially contributing to invasion success in high-irradiance locations via photoprotection. Moreover, the diurnal photoinhibition of photosynthesis, as judged by the maximum photochemical efficiency of PSII $\left(F_{\mathrm{v}} / F_{\mathrm{m}}\right)$ of dark-adapted leaves, was more severe in the natives than in the invasive. With increasing irradiance, the invasive exhibited increased antioxidant activities and higher antioxidant levels to support the adverse conditions of both low- and high-irradiance acclimation. In contrast, the intercellular $\mathrm{CO}_{2}$ concentration $(\mathrm{Ci})$ and stomatal limitation $\left(L_{\mathrm{s}}\right)$ decreased with increases in the net photosynthetic rate $\left(A_{\mathrm{n}}\right)$, stomatal conductance $\left(G_{\mathrm{s}}\right)$, and transpiration rate $\left(T_{\mathrm{r}}\right)$. We speculated that $L_{\mathrm{s}}$ was the main factor inhibiting the $A_{\mathrm{n}}$ for both studied species. These results first indicated that the invasive may occupy new habitats successfully through tolerating shading at low irradiance and out-compete native species through higher $A_{\max }$ and antioxidant levels when irradiance is increased.
\end{abstract}

Keywords: Invasiveness; Irradiance acclimation; Photoinhibition; Photosynthesis; Plasticity

Abbreviations: $A_{\max }$, light-saturated photosynthetic rate; $A_{\mathrm{n}}$, net photosynthetic rate; APX, ascorbate peroxidase; AQY, apparent quantum yield; CAT, catalase; Car, carotenoid; Car/Chl, carotenoid/total chlorophyll; Chl, total chlorophyll; Chl $a$, chlorophyll $a$; Chl $b$, chlorophyll $b$; Chl $a / b$, chlorophyll $a$ /chlorophyll $b$; $C_{\mathrm{i}}$, intercellular $\mathrm{CO}_{2}$ concentration; EEE, excessive excitation energy; $F_{\mathrm{m}}$, maximum fluorescence of dark-adapted state; $F^{\prime}$, maximum fluorescence of light-adapted state; $F_{\mathrm{o}}$, minimal fluorescence of dark-adapted state; $F_{\mathrm{o}}^{\prime}$, minimal fluorescence of light-adapted state; $F_{\mathrm{s}}$, steady-state fluorescence yield; $F_{\mathrm{v}} / F_{\mathrm{m}}$, maximum photochemical efficiency of PSII; FW, fresh weight; $G_{\text {s }}$, stomatal conductance; $\mathrm{H}_{2} \mathrm{O}_{2}$, hydrogen peroxide; LCP, light compensation point; LHC, light-harvesting complex; $L_{\mathrm{S}}$, stomatal limitation; LPO, lipid peroxidation; LSP, light saturation point; LUE, light use efficiency; MDA, malondialdehyde; NPQ, non-photochemical quenching; $\mathrm{O}_{2}{ }^{--}$, superoxide radicals; PPFD, photosynthetic photon flux density; PSII, photosystem II; ROS, reactive oxygen species; SOD, superoxide dismutase; $T_{\mathrm{r}}$, transpiration rate. 


\section{Introduction}

Sunlight is a key limiting resource for photoautotrophic plants. In nature, plants are often exposed to continuous changes in the intensity of light (e.g., sunflecks) (Chazdon and Pearcy, 1991; Rodríguez-López et al. 2014), and their ability to acclimate to external conditions that fluctuate temporally and spatially is of considerable importance for establishing plants in forest ecosystems (Favaretto et al. 2011). Through the process of photosynthesis, light energy is used to produce ATP and NADPH in the light reaction. In the light-independent reaction, carbon is subsequently fixed into carbohydrates, and oxygen is produced (Dai et al. 2009). At high irradiance, the photosynthetic apparatus absorbs excessive excitation energy (EEE), resulting in the inactivation or impairment of the chlorophyll-containing reaction centers (Huang et al. 2014). Consequently, photosynthetic activity is depressed by photoinhibition. Conversely, plants grown at low irradiance generally have a lower light-compensation point (LCP) and light saturation point (LSP) as well as lower synthesis of some components involved in electron transport (generation of ATP and $\mathrm{CO}_{2}$ fixation) (Huang et al. 2011). Nonetheless, the photosystem (especially photosystem II, PSII) is the primary target of photodamage in high- and low-light-grown seedlings, which increases the production of reactive oxygen species (ROS) that aggravate PSII photoinhibition (Nishiyama et al. 2011).

To protect against these phytotoxic symptoms, plants have many photoprotection mechanisms. One mechanism is known as non-photochemical quenching (NPQ) of chlorophyll fluorescence because it competes with photochemistry to quench the little energy that the excited chlorophyll $a$ (Chla) molecules can re-emit as fluorescence (Dai et al. 2009; Giorio et al. 2012). Chlb is mainly contained in the light-harvesting Chl protein complex II (LHCII), and shaded leaves are relatively rich in Chlb (Walters, 2005; Huang et al. 2011). In another mechanism, plants use an antioxidant defense system that consists of oxygen free-radical detoxifying enzymes and other antioxidant compounds to avoid ROS (Huylenbroeck et al. 2000; Shi et al. 2006; Jaleel et al. 2009; Foyer and Shigeoka, 2011). Nonetheless, carotenoids (Car) harvest the EEE, quench the excited state of Chl, and play an effective role in photoprotection (Gill and Tuteja, 2010; Rodríguez-López et al. 2014). Nevertheless, data related to the susceptibility and tolerance of invasive trees to photoinhibition and oxidative stress are scarce.

Accumulating evidence suggests that biological invasions are a major threat to natural 
ecosystems (Daehler, 2003; Allred et al. 2010; Fan et al. 2013; Liao et al. 2013). Thus, the identification of the factors that contribute to the success of invasive plants is important for predicting/controlling potentially invasive plants. The ability to compete with native species for resources (limited or not) may greatly improve the probability of establishment and the overall fitness of the invasive plants ( $\mathrm{Li}$ et al. 2012). However, the mechanisms by which introduced species grow more aggressively in their nonnative ranges than in their native ranges are still not well elucidated. Some studies have reported that some invasive species have a higher light-saturated photosynthetic rate $\left(A_{\max }\right)$, photosynthetic nitrogen use efficiency (PNUE), water use efficiency (WUE), and specific leaf area (SLA) than native species (e.g., Yamashita et al. 2000; Feng et al. 2007; Zheng et al. 2012). Other studies demonstrated that higher carbon gain and growth may enable invasive species to easily out-compete more slowly growing species by facilitating colonization or resource acquisition (Allred et al. 2010 and references therein). However, Palacio-López and Gianoli (2011) used a meta-analysis to reveal that invasive plant species do not display greater phenotypic plasticity (at least for some functional traits) than their native counterparts' responses to light, nutrients, water, carbon dioxide, and support availability. Furthermore, invasive species did not always exhibit increases in $A_{\max }$, PNUE, WUE and SLA. From 24 photosynthetic comparisons between invasive and native species, Daehler (2003) demonstrated that 11 comparisons revealed similar photosynthetic rates for invasive and native species; 7 and 6 comparisons reported higher and lower photosynthetic rates for invasive species, respectively. One explanation is that most of the studies compared phylogenetically unrelated invasive and native species. Phylogenetic relatedness may constrain morphological/physiological variations; closely related plants may share more common traits and more overlapping resource requirements than unrelated species (Feng, 2008; Morais et al. 2012). In contrast, when invasive species are compared with distantly related and hence markedly different counterparts, hypothetical differences in trait plasticity may be equally explained by several traits other than the invasive feature (Palacio-López and Gianoli, 2011). An alternative explanation for the inconsistent results is the intrinsic weakness of the approach of invasive and native comparisons (Grotkopp and Rejmánek, 2007). Consequently, comparisons between related invasive and native species are more meaningful in explaining the invasiveness of invasive species (Zheng et al. 2012; Fan et al. 2013).

Alnus formosana (Burk.) Makino (Betulaceae), an excellent producer of pulpwood and a species 
used in vegetation restoration, is native to Taiwan Province (an island) in China and was introduced to South Africa and other parts of Asia (Zwolinski, 1992; Lai et al. 2012). According to field observations, A. formosana can spread over larger spatial scales than some native species (e.g., $A$. cremastogyne Burk.) in the introduced range, and it has successfully colonized a variety of habitats, including woodlands, riparian forests, and the borders of agricultural fields. Our previous study also demonstrated that A. formosana exhibits higher phenotypic plasticity than A. cremastogyne in three irradiance levels; the increased plasticity is mainly noted in its higher relative growth rate (RGR) but also in its lower leaf area ratio (LAR)(data not shown). The relative performance of invasive plants is environment-dependent, and comparisons between related invasive and native plants in diverse environments are more informative in elucidating plant traits contributing to invasiveness (Allred et al. 2010; Hyldgaard and Brix, 2012; Pintó-Marijuan and Munné-Bosch, 2013). The ability of plants to capture and utilize light is an important determinant of growth potential and fitness (Zheng et al. 2012). Competition for sunlight is an important factor influencing some plant invasions. Yamashita et al. (2000) reported that invasive Bischofia javanica achieves a rapid photosynthetic acclimation when transferred from shade to a sunny environment by minimizing photoinhibition in existing shade leaves and rapidly deploying new sun leaves with high photosynthetic capacity. Thus, it is reasonable to hypothesize that A. formosana might have an increased $A_{\max }$ and/or antioxidant functions to enhance photosynthesis compared with its native congener. However, the physiological mechanisms associated with the higher performance of $A$. formosana were unclear, and the relationship between the plasticity of physiological traits and invasiveness was also not assessed.

Against this background, we examine possible strategies of competition and tolerance that may be responsible for or aid in the successful invasion of $A$. formosana at three irradiances. The main objectives of this study were to (i) explore which physiological traits contributed to the higher performance of the invasive and (ii) analyze the relationships between invasiveness and plasticity of these physiological traits and performance. The results from this work will contribute to the scientific discussion of the differences between the invasive and native species in photosynthetic acclimation and photoprotection strategies.

\section{Materials and methods}




\section{Site description}

The experiment was performed in Lingyan Mountain Botanical Garden $\left(31^{\circ} 01^{\prime} \mathrm{N}, 103^{\circ} 35^{\prime} \mathrm{E}\right.$, and 800 m.a.s.1.) of Sichuan Agricultural University (SICAU) located in Dujiangyan County, Sichuan Province in southwest China. The mean annual temperature is $15.2^{\circ} \mathrm{C}$, and the annual accumulated temperature $\left(\geq 10^{\circ} \mathrm{C}\right)$ is $4677.1^{\circ} \mathrm{C}$, with a mean of $26.5^{\circ} \mathrm{C}$ in the hottest month (July) and $5.6^{\circ} \mathrm{C}$ in the coolest month (January). The annual precipitation of the base ranges from 1300 to $1800 \mathrm{~mm}$, with a dry period lasting from November to February. A heavy fog, which usually starts at ca. 23:00 and lasts to ca. 10:00, is present almost daily from October to February.

We conducted this study in a 5-year-old Alnus-dominated heath originating from an illegal deforestation in a Pinaceae-Alnus forest in Dujingyan-Longchi National Park (DLNP), Sichuan Province. A. cremastogyne (including adult trees and young saplings) are native species with a stature similar to that of $A$. formosana in this region. This species has sympatric distributions with $A$. formosana and also occurs in various habitats, such as cut-over areas, forest gaps, and forest canopies. Based on our field observations, the native congener is typically distributed in slightly shaded environments and rarely in low- or high-irradiance environments. However, A. formosana has high density at ca. $50-100 \%$ irradiances, whereas it is still common at ca. $20-50 \%$ irradiances. A. formosana is also found at ca. 10\% irradiance. The seeds of the studied species were collected from natural populations from mid-to-late December 2008 to mid-January 2009 at two sites $20 \mathrm{~km}$ apart from each other around Dujingyan city, Sichuan Province, China.

\section{Experimental treatments}

In February 2009, the seeds of the studied species were sown at a seedbed in a greenhouse. In April, when the seedlings of the species were ca. $15 \mathrm{~cm}$ tall (with three leaf pairs), similarly sized vigorous seedlings were transplanted singly into $15 \mathrm{dm}^{3}$ plastic pots $(30 \mathrm{~cm}$ in diameter and $23 \mathrm{~cm}$ in height) located under shade netting that provided 50\% irradiance. The pots were filled with equal proportions of river sand and forest topsoil. Topsoil was used to provide a natural supply of macroand micro-nutrients, and the river sand provided a texture with adequate drainage and facilitated the harvest of fine roots. After 20 days of growth in 50\% irradiance, all seedlings were transitioned to full sunshine by removing the shade net. The seedlings were divided randomly into three groups, and each group (20 seedlings) was grown at one of the three irradiances $(12.5 \%, 56.2 \%$, and 100\%). The seedlings were watered with tap water (ca. $3 \mathrm{dm}^{3}$ ) every three day and fertilized with complex 
compound fertilizer $(15 \% \mathrm{~N}, 15 \% \mathrm{P}$, and $15 \% \mathrm{~K})$ at $2 \mathrm{~g}$ per pot. On June $8^{\text {th }}$, the transplanting work was completed.

The soil in the area is a nutrient-rich, poor-to-rapidly drained, powdery, yellow-brown loam with a $\mathrm{pH}$ value between 5.5 and 6.5. Before fertilization, the organic matter content, including total $\mathrm{N}, \mathrm{P}$ and $\mathrm{K}$ and available $\mathrm{N}, \mathrm{P}$ and $\mathrm{K}$, in the growing substrate were $19.32 \mathrm{~g} \mathrm{~kg}^{-1}, 813.18 \mathrm{mg} \mathrm{kg}^{-1}, 235.26$ $\mathrm{mg} \mathrm{kg}{ }^{-1}, 39.32 \mathrm{mg} \mathrm{kg}^{-1}, 10.36 \mathrm{mg} \mathrm{kg}^{-1}$, and $58.54 \mathrm{mg} \mathrm{kg}^{-1}$, respectively. After fertilization, the contents of available $\mathrm{N}, \mathrm{P}$, and $\mathrm{K}$ were $45.65,26.46$, and $76.23 \mathrm{mg} \mathrm{kg}^{-1}$, respectively.

The experiment, which involved simulating the light regimes of forest openings (cut-over areas), forest gaps, and forest canopies in DLNP of China, was conducted in three large shade houses (40 m $\times 4.0 \mathrm{~m} \times 1.5 \mathrm{~m}$ ) that were constructed of steel tubes in an open site. The lower $30 \mathrm{~cm}$ of each shade house remained open to facilitate airflow. The light intensity in each shade house was controlled by different layers of black nylon shade netting, including no netting to create $100 \%$ irradiance (full sunlight). Two plots, a forest gap and a forest canopy, were selected in the experimental area. These plots were $200 \mathrm{~m}$ apart at $750 \mathrm{~m}$.a.s.l. The two plots boast the same or similar exposure, inclination, and edaphic conditions. Quantum sensors and a Li-1400 Datalogger (LI-Cor Inc., Lincoln, NE, USA) were used to measure photosynthetic photon flux density (PPFD) in the two plots and two shade houses (Supplementary figure S1) during a clear day. The relative irradiance above each sample individual was calculated as the ratio of the light intensity above it to that in the open site. The PPFDs of the forest gaps and forest canopies were $54.6 \pm 0.04 \%$ and $10.3 \pm 0.90 \%$, respectively, during full sunlight exposure, whereas the PPFDs of the two shade houses reached $56.2 \pm 1.03 \%$ irradiance (medium shade) and $12.5 \pm 0.21 \%$ irradiance (excessive shade). These results suggest that the simulated sunlight environment resembled that of the sample lands. To avoid position effects, the pots were arranged in the central part of each house and randomized fortnightly within each shade house throughout the experiment. As in most experiments that control irradiance (Feng, 2008; Zheng et al. 2012), we had no replication of the shade house with similar irradiance, and the seedlings in each shade house were used as replicates for statistical analyses.

\section{Light-response curves}

From August $18^{\text {th }}$ to $25^{\text {th }}$, on clear-sky days, randomly selected, new fully expanded leaves (the fifth or sixth leaf from the top) of three individuals per species and treatment were analyzed. The photosynthetic light-response curves $(A / \mathrm{PPFD})$ were obtained by decreasing the PPFD in fifteen 
sequential steps from strong to weak $(2000,1800,1600,1400,1200,1000,800,600,400,200,100$, $50,20,10$ and $0 \mu \mathrm{mol} \mathrm{m}^{-2} \mathrm{~s}^{-1}$ ) at $25^{\circ} \mathrm{C}$. The leaf tissues were initially exposed to a low ambient $\mathrm{CO}_{2}$ concentration ( $50 \mu \mathrm{mol} \mathrm{mol}^{-1}$ air for $5 \mathrm{~min}$ to allow for stomatal opening); the $A / \mathrm{PPFD}$ curves were then produced at a $\mathrm{CO}_{2}$ concentration of $400 \mu \mathrm{mol} \mathrm{mol}^{-1}$ air. The $A_{\max }$, apparent quantum yield (AQY), LCP, and LSP were determined from these curves by fitting the data to a modified rectangular hyperbole model proposed by Ye (2007). The model was fitted to the data using nonlinear regression analysis by applying iterative curve fitting (minimum least square difference) using the Microsoft Excel Solver tool (Microsoft Corporation, Redmond, WA, USA). It was assumed that the LSP corresponded to the PPFD required to achieve $90 \%$ of the $A_{\max }$. The relative humidity of the air in the leaf chamber was controlled at ca. $70 \%$, and leaf temperature was maintained at $25 \pm 0.4^{\circ} \mathrm{C}$ during all measurements.

\section{Gas exchange and chlorophyll fluorescence measurements}

The $A_{\mathrm{n}}$, stomatal conductance $\left(G_{\mathrm{s}}\right)$, transpiration rate $\left(T_{\mathrm{r}}\right)$, and intercellular $\mathrm{CO}_{2}$ concentration $\left(C_{\mathrm{i}}\right)$ were measured between 9:00 and 10:30 am from the same leaves (and time periods) using a Li-6400 Portable Photosynthesis System (Li-Cor, Lincoln, NE, USA) with constant irradiation (600 $\mu \mathrm{mol}$ photons $\mathrm{m}^{-2} \mathrm{~s}^{-1}$ ). The stomatal limitation $\left(L_{\mathrm{s}}\right)$ of $A$ is an estimate of the proportion by which actual $G_{\text {s }}$ decreases $A$ relative to what $A$ would be assuming infinite conductance between the atmosphere and the leaf sub-stomatal airspace $\left(A^{0}\right)$ and is typically estimated from $A$ vs. $C_{\mathrm{i}}$ curves using the following relationship (Farquar and Sharkey, 1982): $L_{\mathrm{s}}=1-A / A^{0} . A$ is the rate of carbon assimilation at the measurement $\left[\mathrm{CO}_{2}\right]$ and based on the actual $G_{\mathrm{s}}$, and $A^{0}$ is photosynthesis assuming infinite $G_{\mathrm{s}}$ (i.e., when $C_{\mathrm{i}}=$ atmospheric $\left[\mathrm{CO}_{2}\right]$ ). The light use efficiency (LUE) was calculated by $L U E=$ $A_{n} / P P F D$.

Chlorophyll fluorescence was measured simultaneously with the gas exchange measurements for leaves using a fluorometer leaf chamber (6400-40, Li-Cor Inc. Lincoln, NE, USA). The initial fluorescence $\left(F_{\mathrm{o}}\right)$ was measured by switching on the modulated irradiation of $0.6 \mathrm{kHz}$. PPFD was less than $0.1 \mu \mathrm{mol} \mathrm{m} \mathrm{m}^{-2} \mathrm{~s}^{-1}$ on the leaf surface, which was adapted to darkness for $30 \mathrm{~min}$. The maximal fluorescence $\left(F_{\mathrm{m}}\right)$ was measured at $20 \mathrm{kHz}$ with a 1 -s pulse of $6000 \mu \mathrm{mol} \mathrm{m}^{-2} \mathrm{~s}^{-1}$ of white light. The maximum photochemical efficiency of PSII $\left(F_{\mathrm{v}} / F_{\mathrm{m}}\right)$ was calculated as $F_{\mathrm{v}} / F_{\mathrm{m}}=$ $\left(F_{\mathrm{m}}-F_{\mathrm{o}}\right) / F_{m}$. During illumination, the steady-state fluorescence $\left(F^{\prime}\right)$ was obtained. The maximal fluorescence $\left(F^{\prime}\right)$ was also determined by applying a saturating pulse. The non-photochemical 
quenching coefficient (NPQ) was calculated as NPQ $=\left(F_{\mathrm{m}}-F_{\mathrm{m}}^{\prime}\right) / F_{\mathrm{m}}^{\prime}$.

All of the above photosynthetic measurements were repeated five times, so the photosynthetic parameters for each replicate were computed as the average values for the measured days. Within each time period, measurements were carried out in blocks in an attempt to minimize the effects of potential variations of the environmental conditions.

\section{Determination of photosynthetic pigment concentrations}

Leaf discs were collected on clear-sky days, flash frozen in liquid nitrogen, and subsequently stored at $-80^{\circ} \mathrm{C}$ until analysis. Subsequently, the plant material was ground. To calculate the $\mathrm{Car} / \mathrm{Chl}$ ratio, total Chl, Chla, Chl $b, \mathrm{Chl} a / b$ and Car concentrations were determined spectrophotometrically after extraction overnight in the darkness in $80 \%$ ethanol according to Lichtenthaler (1987).

\section{Hydrogen peroxide content and lipid peroxidation assay}

Fully expanded and exposed leaves were randomly selected from each replication and treatment to measure the $\mathrm{H}_{2} \mathrm{O}_{2}$ and MDA levels. The $\mathrm{H}_{2} \mathrm{O}_{2}$ concentration was estimated following the method of Patterson et al. (1984). The absorbance of the solution was measured at $410 \mathrm{~nm}$ against blanks that had been similarly prepared but did not contain plant tissue. LPO in plant tissue was determined by measuring MDA, a major thiobarbituric acid-reactive species (Heath and Packer, 1968). The absorbance of the supernatant was read at $532 \mathrm{~nm}$ and corrected for non-specific absorbance at 600 nm.

\section{Antioxidant activity assays}

Plant samples $(0.5 \mathrm{~g})$ were homogenized in $10 \mathrm{ml}$ of chilled $0.1 \mathrm{M}$ potassium phosphate buffer ( $\mathrm{pH}$ 7.0) under ice-cold conditions. The homogenate was filtered through four layers of cheesecloth and centrifuged at $15,000 \times \mathrm{g}$ at $4^{\circ} \mathrm{C}$ for $30 \mathrm{~min}$. The supernatant was stored at $4^{\circ} \mathrm{C}$ before use in protein determination and enzyme activity assays. The protein content in the homogenate was determined using bovine serum albumin as a standard. All spectrophotometric analyses were performed at $25^{\circ} \mathrm{C}$ using a UV-VIS spectrophotometer (Model UV-190, Shimadzu, Japan).

Total superoxide dismutase (SOD, EC 1.15.1.1) activity was determined by measuring its ability to inhibit the photochemical reduction of nitroblue tetrazolium (Beauchamp and Fridovich, 1971). One SOD unit was calculated as the amount of enzyme required to inhibit the photoreduction of NBT by $50 \%$ at $25^{\circ} \mathrm{C}$. Tubes containing the reaction mixture were incubated under two $15 \mathrm{~W}$ fluorescent lamps for $15 \mathrm{~min}$ and then transferred to the dark for $15 \mathrm{~min}$. The absorbance was read at 
$560 \mathrm{~nm}$. The SOD activity is expressed as $\mathrm{U} \mathrm{mg}^{-1}$ protein. Catalase (CAT, EC 1.11.1.6) activity was determined by directly measuring the rate of $\mathrm{H}_{2} \mathrm{O}_{2}$ conversion to $\mathrm{O}_{2}$ at $240 \mathrm{~nm}$ according to the method of Cakmak and Marschner (1992). Enzyme activity was calculated using an extinction coefficient of $39.4 \mathrm{mM}^{-1} \mathrm{~cm}^{-1}$. Ascorbate peroxidase (APX, EC 1.11.1.11) activity was measured as the decrease in absorbance at $290 \mathrm{~nm}$, which results from ascorbate oxidation (Nakano and Asada 1981). Enzyme activity was calculated using an extinction coefficient of $2.8 \mathrm{mM}^{-1} \mathrm{~cm}^{-1}$. The CAT and APX activities are expressed as $\mathrm{U} \mathrm{mg}^{-1}$ protein.

\section{Statistical analyses}

The data were statistically analyzed following either a randomized block design ( $A$, gas exchange parameters and $\mathrm{Chl}$ fluorescence parameters) or a completely randomized design (the remaining parameters) with four to six replicates. Statistical analyses were performed with the software Statistical Package for the Social Sciences (SPSS) version 17.0 (SPSS Inc., IL, USA). A two-way analysis of variance (ANOVA) was used to assess the effects of species (S), irradiance (I), and their interaction $(\mathrm{S} \times \mathrm{I})$ on each variable evaluated in this study. One-way ANOVAs (Duncan test) were used to assess the differences among species at the same irradiance and the differences among irradiances for the same species in each variable. Data are presented as the means \pm one standard error (SE).

\section{Results}

\section{Photosynthesis}

To explore the photosynthetic characteristics of invasive A. formosana and its native congener, light-response curves of $A$ /PPFD were measured. The patterns of the light-response curves were similar for all three irradiances (Fig. 1). $A_{\mathrm{n}}$ variations for both studied species exhibited similar trends, increasing rapidly up to $500 \mu \mathrm{mol} \mathrm{m} \mathrm{m}^{-2} \mathrm{~s}^{-1}$ PPFD then rising slowly until reaching their maximum values $\left(8.56,7.30\right.$, and $5.40 \mu \mathrm{mol} \mathrm{CO}_{2} \mathrm{~m}^{-2} \mathrm{~s}^{-1}$ for $A$. formosana and 7.24, 6.70, and 4.80 $\mu \mathrm{mol} \mathrm{CO} \mathrm{Cm}^{-2} \mathrm{~s}^{-1}$ for $A$. cremastogyne at $100 \%, 56.2 \%$, and $12.5 \%$ irradiances, respectively) of 2000 $\mu \mathrm{mol} \mathrm{m} \mathrm{m}^{-1}$. Plants grown at higher irradiances had higher $A_{\mathrm{n}}$ than those grown at low irradiances.

Species [except for AQY $(F=3.341, P=0.632)]$ and irradiance significantly $(P<0.05$ for AQY, $P<0.01$ for others) affected photosynthesis variables evaluated in this study according to a two-way ANOVA (Fig. 2). The interactions $(S \times I)$ between species and irradiance were also significant for 
the variables $\left(F=8.409, P=0.005\right.$ for $A_{\max } ; F=6.278, P=0.014$ for LCP $)$ except LSP $(F=0.989$, $P=0.400)$ and AQY $(F=0.477, P=0.632)$, indicating that the patterns of the differences in $A_{\max }$, LSP, and LCP between species were different at three irradiances. For example, A. formosana compared with its native congener exhibited significantly higher $A_{\max }$ and LSP at all studied irradiances (Fig. 2B and C). However, the invasive had lower LCP than the natives only at $12.5 \%$ irradiance $(F=36.24, P=0.004)$ but not at $100 \%$ and $56.2 \%$ irradiances (Fig. 2D). For both studied species, $A_{\max }$, LSP, and LCP increased significantly with increasing irradiance and peaked at $100 \%$ irradiance, whereas AQY was not significantly $(F=1.500, P=0.296$ for $A$. formosana $F=2.700, P$ $=0.146$ for A. cremastogyne) influenced by three irradiances (Fig. 2A).

\section{Maximum photochemical efficiency of PSII (Fv/Fm) and diurnal variation of NPQ}

Photoinhibition of PSII can be easily detected in vivo by a decrease in the 'dark-adapted' ratio of variable to $F_{\mathrm{v}} / F_{\mathrm{m}}$ (Favaretto et al. 2011). Thus, decrease in the $F_{\mathrm{v}} / F_{\mathrm{m}}$ ratio, which represents the maximum photochemical efficiency of PSII, is often used to estimate the degree of photoinhibition. In this study, the patterns of the $F_{\mathrm{v}} / F_{\mathrm{m}}$ ratios were similar for all three irradiances (Fig. 3). As time progressed, the $F_{\mathrm{v}} / F_{\mathrm{m}}$ ratio was significantly $(F=11.545, P=0.009$ for $A$. formosana; $F=9.348, P$ $=0.014$ for $A$. cremastogyne) influenced by irradiances (Fig. 3A and B). For both studied plants, the $F_{\mathrm{v}} / F_{\mathrm{m}}$ ratio decreased significantly with increased irradiance, reached the lowest points at ca. 13:00 $\mathrm{h}$ (0.77, 0.79 , and 0.73 for $A$. formosana and $0.75,0.79$, and 0.71 for $A$. cremastogyne at $100 \%, 56.2 \%$ and $12.5 \%$ irradiances, respectively), and then increased until rebounding to the level of the morning at ca. 19:00 h. For $A$. formosana, the $F_{\mathrm{v}} / F_{\mathrm{m}}$ ratio ranged from 0.77 to 0.83 at $100 \%$ and $56.2 \%$ irradiances and was significantly higher than the ratio at $12.5 \%$ irradiance $(0.73-0.81)$. For $A$. cremastogyne, the values $(0.71-0.79)$ at $12.5 \%$ irradiance were slightly lower than those for the invasive.

For both studied species, NPQ increased continuously with increasing irradiance, whereas these variables peaked at ca. 13:00 h $(4.53,2.79$, and 1.45 for native species and 3.58, 2.14, and 0.61 for invasive species at $100 \%, 56.2 \%$, and $12.5 \%$ irradiances, respectively) and then rapid decreased to morning levels (Fig. 3C and D). Similarly to $F_{\mathrm{v}} / F_{\mathrm{m}}$, the levels of NPQ at $100 \%$ irradiance were markedly $(P<0.05)$ higher than the levels at $56.2 \%$ and $12.5 \%$ irradiances for both plants. Further, the natives exhibited a broader NPQ ascendant range and a larger max NPQ than the invasive at all studied irradiances. 


\section{Gas exchange parameters and light use efficiency}

Irradiance $(P<0.01)$ and species [except for $C_{\mathrm{i}}(F=0.301, P=0.593)$ and $L_{\mathrm{s}}(F=1.898, P=$ 0.193)] significantly affected all gas exchange parameters in this study based on two-way ANOVA (Fig. 4A-F). However, the interactions between species and irradiance were not significant for most of the variables (e.g., $F=0.729, P=0.503$ for $T_{\mathrm{r}} ; F=0.174, P=0.842$ for $G_{\mathrm{s}} ; F=0.032, P=0.968$ for $C_{\mathrm{i}} ; F=0.844, P=0.454$ for $\left.L_{\mathrm{s}}\right)$ except $A_{\mathrm{n}}(F=8.200, P=0.006)$, indicating species differences in plasticity for these variables. With increasing irradiance, the values of $A_{\mathrm{n}}, T_{\mathrm{r}}$, and $G_{\mathrm{s}}$ increased for A. formosana and its native congener and was significantly increased for the invasive compared with the natives at three irradiances (except $A_{\mathrm{n}}$ at $100 \%$ and $12.5 \%$ irradiances and $G_{\mathrm{s}}$ at $26.5 \%$ irradiance) (Fig. 4A, C, and E). For both studied species, however, the values of $C_{\mathrm{i}}, L_{\mathrm{s}}$, and LUE decreased with increasing irradiance, although the differences were not significant $(P>0.05)$ at $100 \%$ and $56.2 \%$ irradiances [except $\operatorname{LUE}(P=0.023)$ for A. cremastogyne]. Further, the differences in of $C_{\mathrm{i}}, L_{\mathrm{s}}$, and LUE values between invasive and native species were not significant at three irradiances (Fig. 4B, D, and F).

\section{Photosynthetic pigments}

The responses of Chla, Chl $b, \mathrm{Chl}$, and Car to irradiances significantly $(P<0.01)$ differ between species, whereas the responses of Chla/b and Car/Chl did not differ (Fig. 5A-F). The interactions between species and irradiance were significant for the variables $(F=14.450, P=0.001$ for Chla/b; $F=24.551, P=0.000$ for $\mathrm{Chl} b ; F=8.294, P=0.005$ for Chl $)$ except Chl $a(F=2.832, P=0.098)$, $\operatorname{Car}(F=3.040, P=0.085)$ and $\mathrm{Car} / \mathrm{Chl}(F=4.570, P=0.033)$. For both studied species, Chla, Chl $b$, and total $\mathrm{Chl}$ decreased, whereas Car and Car/Chl increased with increasing irradiance, although the differences in these variables between invasive and native congeners were not significant at $100 \%$ and 56.2\% irradiances (except $\mathrm{Car}$ and $\mathrm{Chl}$ in natives). Similarly, the difference in Chla/b between $A$. formosana and its native species was not significant at $100 \%$ and $56.2 \%$ irradiances, whereas Chla/b increased in invasive with increasing irradiance (Fig. 5B). Furthermore, compared with its native congener, A. formosana exhibited significantly increased Chlb $(F=135.779, P=0.000)$, Chl $(F=$ $12.436, P=0.024)$ and $\operatorname{Car}(F=27.923, P=0.006)$ but markedly lower Chla/b $(F=42.135, P=$ $0.003)$ and $\mathrm{Car} / \mathrm{Chl}(F=46.154, P=0.002)$ at $12.5 \%$ irradiance as well as slightly higher Chl $a(F=$ 9.076, $P=0.039)$ and $\mathrm{Chl}(F=8.770, P=0.041)$ at $100 \%$ irradiance.

\section{Lipid peroxidation and antioxidative enzyme activity}


Both irradiance $(P<0.01)$ and species $\left(P<0.05\right.$ for $\mathrm{H}_{2} \mathrm{O}_{2}, P<0.01$ for others $)$ had significant effects on all antioxidant variables measured in this study based on a two-way ANOVA (Fig. 5A-F). The interactions between irradiance and species were not significant for the variables $(F=2.870, P$ $=0.096$ for $\mathrm{MDA} ; F=1.802, P=0.207$ for $\mathrm{SOD} ; F=0.322, P=0.731$ for $\mathrm{CAT})$ except $\mathrm{APX}(F=$ 0.368; $P=0.038)$. With increasing irradiance, $\mathrm{H}_{2} \mathrm{O}_{2}$, SOD, CAT, and APX markedly $(P \leq 0.01)$ increased for all studied species, although the differences were not significant at $56.2 \%$ and $12.5 \%$ irradiances [except $\mathrm{H}_{2} \mathrm{O}_{2}(P=0.026)$ and APX $(P=0.007)$ in A. formosana and CAT $(P=0.007)$ and APX $(P=0.001)$ in A. cremastogyne], whereas MDA in A. formosana revealed no self-evident variation $(F=1.571, P=0.283$; Fig. $6 \mathrm{~B})$. Moreover, compared with its native congener, $A$. formosana revealed significantly $(P<0.01)$ higher MDA, SOD, and APX at all studied irradiances and CAT only at $100 \%$ and $12.5 \%$ irradiances.

\section{Discussion}

Why some introduced species become invasive and others do not is the central open question of aggression biology, and general trends indicate that increased reproductive success makes a species more invasive? When performing aggression studies, it is important to include an in-depth physiological characterization of the plant species under investigation (Li et al. 2012; Fan et al. 2013). Two characteristics of functional traits are believed to support the process of invasive species becoming invasive: higher prevalence of competitively advantageous traits and greater phenotypic plasticity that permits the species to survive the colonization period and to spread within a broad range of environments (Allred et al. 2010; Hyldgaard and Brix, 2012; Pintó-Marijuan and Munné-Bosch, 2013). Thus, we discuss photosynthesis adjustment and the production of antioxidants as the two mechanisms that help plants to cope with suboptimal conditions found in various irradiance conditions.

On the one hand, plants can change their photosynthetic characteristics to acclimate to fluctuating irradiance (Peltzer and Polle, 2001; Rodríguez-López et al. 2014). As shown in Fig. 2, $A_{\max }$, LSP, and LCP in both studied species were significantly increased at high irradiance (100\% irradiance) than low irradiance. Similar results were obtained in studies of certain tropical rainforest tree species (e.g., Walters, 2005 and references therein; Favaretto et al. 2011), indicating that light-demanding species may protect their photosynthetic apparatus by using EEE in photosynthesis. 
The excessive-shade treatments decreased the LCP (Fig. 2D). Plants that are acclimated to lower irradiance tend to have a lower photosynthetic capacity and LCP (Huang et al. 2011). Krause et al. (2001) and Zheng et al. (2012) demonstrate that the $A_{\max }$ was positively correlated with the net assimilation rate and $\mathrm{N}$ allocation to photosynthesis in the invasive. Thus, invasive species may increase $\mathrm{N}$ allocation to photosynthesis by reducing accumulation of $\mathrm{N}$-based defensive chemicals due to evolutionary responses in the absence of natural enemies (Feng, 2008; Fan et al. 2013). In this work, the increased $A_{\max }$ of $A$. formosana compared with its native congener (Fig. 2C) may contribute to its higher RGR through increasing NAR, one of the determinants of RGR. In our previous work, we also reported positive correlations between RGR, total biomass, and $A_{\max }$ (data not shown). The increased RGR of $A$. formosana can facilitate the growth of ramets and branches, increasing crown area and total leaf area, which might provide a competitive advantage to the invasive by shading native plants (Grotkopp and Rejmánek, 2007; Feng et al. 2007).

Dark-adapted $F_{\mathrm{v}} / F_{\mathrm{m}}$ reflects the potential quantum efficiency of the PSII and is used as a sensitive indicator of plant photosynthetic performance, with optimal values of approximately 0.83-0.85 measured for most plant species (Maxwell and Johnson, 2000). Any value of $F_{\mathrm{v}} / F_{\mathrm{m}}$ that is below the unstressed values is considered representative of photoinhibition. A decrease in this number designates a stressful condition and a reduction in the maximum quantum efficiency of PSII, which thereby compromises the plant's photosynthetic potential (Favaretto et al. 2011). In early morning, the irradiance was relatively low, and the $F_{\mathrm{v}} / F_{\mathrm{m}}$ value was high (Fig. 3A and B). At noon, the irradiance increases to a high level, inducing PSII photoinhibition. Because PSII photoinhibition results from an imbalance of photodamage and repair, the decrease in $F_{\mathrm{v}} / F_{\mathrm{m}}$ (at ca. 13:00 h) suggests that the rate of PSII photodamage largely exceeds the rate of repair under strong irradiance. The lower $F_{\mathrm{v}} / F_{\mathrm{m}}$ could be considered as a positive adaptation for down-regulation of the photosynthetic excitation pressure and might be stimulated by photoprotective mechanisms, including non-photochemical dissipation of $\mathrm{Chl}$ excitation or state transition (Campos et al. 2014 and references therein); the latter describes a reversible physiological mechanism that enables plants to optimize the photosynthetic electron transport for rapidly fluctuating light conditions (Papageorgiou and Govindjee, 2011), such as those in an undercover canopy. On a clear day, the relative humidity decreases, and the vapor pressure deficit increases at noon compared with the morning. As a result, leaves might close their stomata to reserve water potential. The decrease in 
stomatal conductance induces a decline in $\mathrm{CO}_{2}$ fixation (Farquar and Sharkey, 1982), which could increase the generation of ROS that induce photooxidative damage to PSII (Huang et al. 2014). To avoid severe PSII photoinhibition under high irradiance, plants might reduce their absorption of light energy to decrease the rate of photodamage to PSII. Similarly to $A_{\max }, A$. formosana exhibited higher $F_{\mathrm{v}} / F_{\mathrm{m}}$ and LSP at three irradiances but lower LCP only at $12.5 \%$ irradiance compared with its native congener (Fig. 2 and 3). One explanation for this result is that the invasive are capable of achieving photosynthesis at low irradiances. An alternative explanation is that the invasive can quickly attain canopy stature after canopy gap formation, which is potentially consistent with its LUE (Daehler, 2003; Fan et al. 2013).

NPQ can represent the energy that cannot be utilized to transport photosynthetic electrons being dissipated harmlessly as heat energy from PSII antennae. In this study, NPQ values in both species were increased at high irradiance compared with low irradiance (Fig. 3C and D). The lower NPQ in $56.2 \%$ and $12.5 \%$ irradiance plants indicates that these plants effectively reduced the irradiance heat and efficiently utilized the energy absorbed by antenna pigments (Giorio et al. 2012; Rodríguez-López et al. 2014). The higher NPQ in 100\% irradiance plants indicates that the energy absorbed in the physiological range of irradiances was considerably higher than photochemical utilization, which causes inhibition of photosynthetic capacity (Huang et al. 2014). In contrast to its higher $A_{\max }$ and $F_{\mathrm{v}} / F_{\mathrm{m}}$, the invasive species exhibited lower NPQ compared with its native congeners at three irradiances, indicating that high levels of light energy that exceed photosynthetic capability are not transformed into thermal dissipation (Huang et al. 2011). Thus, A. formosana may protect the photosynthetic apparatus via increased $A_{\max }$. However, the opposite trends occurred in the native species; thus, part of the EEE in the PSII antennae was potentially dissipated as heat via the activation of non-radiative dissipation (Demmig-Adams, 2003).

Guard cell protoplasts contain both PSI and PSII, and stomata are formed by two guard cells. The stomata minimize water loss and optimize the $\mathrm{CO}_{2}$ absorption to acclimate to light-induced stress (Araújo et al. 2011). Studies have demonstrated that sunlight plays a vital role in the control of stomatal behavior. In this study, $A_{\mathrm{n}}$ was highly and positively correlated with $G_{\mathrm{s}}\left(r=0.78^{* *}\right)$ and also highly and negatively correlated with $C_{\mathrm{i}}\left(r=-0.76^{* *}\right)$ and $L_{\mathrm{s}}\left(r=-0.75^{* *}\right)$. Thus, we speculate that the decrease in $A_{\mathrm{n}}$ that occurs with decreasing irradiance might be due to stomatal factors. As reported by Farquhar and Sharkey (1982), $C_{\mathrm{i}}$ and $L_{\mathrm{s}}$ can assess whether $G_{\mathrm{s}}$ is the main factor 
inhibiting $A_{\mathrm{n}}$. They hypothesized that $C_{\mathrm{i}}$ and $A_{\mathrm{n}}$ decreased (in the same direction) and that $L_{\mathrm{s}}$ increased because the decrease in $A_{\mathrm{n}}$ is the main result of the decrease in $G_{\mathrm{s}}$; however, this is referred to the rate of $\mathrm{CO}_{2}$ assimilation versus the intercellular partial pressure of $\mathrm{CO}_{2}$ response curves. By contrast, fluctuations in $P_{\mathrm{n}}$ but not in $G_{\mathrm{s}}$ are determined by the photosynthetic activity of the mesophyll cells. With decreasing irradiance, $G_{\mathrm{s}}{ }^{\prime} A_{\mathrm{n}}$, and $T_{\mathrm{r}}$ in both studied species gradually decreased, possibly resulting from an increase in $\left[\mathrm{Ca}^{2+}\right]_{\mathrm{cyt}}$. Changes in $\left[\mathrm{Ca}^{2+}\right]_{\text {cyt }}$ are important for light-induced stomatal opening. Light sensing is transduced by phototropins, which are plasma membrane-associated serine/threonine photoreceptor kinases undergoing autophosphorylation and regulating $\left[\mathrm{Ca}^{2+}\right]_{\text {cyt }}\left(\mathrm{O}^{\prime}\right.$ Carrigana et al. 2014). Generally, the stomata of well-adapted plants play a relatively small role in determining the photosynthetic rate, composing less than ca. $20 \%$ of the total photosynthetic limitation (Jones, 1985). Thus, $G_{\mathrm{s}}$ was not important in explaining the interspecific difference in $A_{\max }$, although it is significantly correlated with $A_{\max }\left(r=0.89^{* *}\right)$. In this study, $A$. formosana had a higher $G_{\mathrm{s}}$ than its native congener, whereas its $C_{\mathrm{i}}$ was not higher. $A_{\max }$ decreased significantly with increasing $C_{\mathrm{i}}$. The results further indicated that the ability to use intercellular $\mathrm{CO}_{2}$ was more important than the ability to supply $\mathrm{CO}_{2}$ (associated with $G_{\mathrm{s}}$ ) for explaining the difference in $A_{\max }$ between invasive and native species, thus again confirming the importance of $\mathrm{N}$ allocation (Zheng et al. 2012; Huang et al. 2014).

Leaf Chl content is well established as a common reference system when physiological reactions are quantified. Light energy absorbed by Chl molecules can undergo three fates: (1) the molecules can be used to drive photosynthesis; (2) excess energy can be dissipated as heat; or (3) excess energy can be re-emitted as light-Chl fluorescence. Thus, photoprotection mechanisms could differ between leaves in the full sun and those in shade. Many studies have demonstrated that plants grown under shaded conditions optimize their effectiveness of light absorption by increasing the pigment density per unit leaf area (e.g., Dai et al. 2009; Favaretto et al. 2011; Huang et al. 2011). In this study, the shaded plants at 56.2\% and $12.5 \%$ irradiances in both studied species had higher Chl levels (Chla, Chlb, and Chl) with high levels of LHC to absorb as much light as possible. In general, increased irradiance resulted in a reduction in the Chl content, especially the Chl $b$ content (Fig. 5). Lower Chlb levels in high-light leaves facilitate the photoprotection of the reaction center of PSII by reducing the light absorption (Walters, 2005). Further, Chl $b$ is most abundant in the antennae of the LHCII, whereas Chla is involved in determining the photosynthetic activity. Compared with its 
native congener, $A$. formosana exhibited significantly higher Chla only at $12.5 \%$ irradiance, at least partially explaining the higher $A_{\max }$, LSP, and LCP (Fig. 2). The reductions we observed in the Chla/b ratio in $A$. formosana plants grown at $12.5 \%$ irradiance were due primarily to increases in Chlb content (Fig. 5C) and are most likely due to changes in the organization of both light harvesting and electron transport components (Dai et al. 2009). The marked increase in leaf Chl content only at $12.5 \%$ irradiance demonstrated the invasive species' ability to maximize the light harvesting capacity in low-light growth conditions (Fig. 5E).

On the other hand, as lipid-soluble antioxidants, Car performs three major functions in plants: (1) absorbs light at a wavelength and transfer it to the Chl (an accessory light harvesting role); (2) protects the photosynthetic apparatus by quenching harmful free radicals (an antioxidant function); and (3) assembles PSI and stabilizes light harvesting complex proteins (a structural role) (Gill and Tuteja, 2010; Zheng et al. 2012; Rodríguez-López et al. 2014). Cars within the photosynthetic apparatus are known to quench ${ }^{\mathrm{t}} \mathrm{O}_{2}$, but the photosynthetic growth of cells lacking Car suggests the presence of other mechanisms to protect cells from ${ }^{\mathrm{t}} \mathrm{O}_{2}$ damage. In this study, the relative increment in Car with increasing irradiance was higher for the invasive species than the native species (at $100 \%$ irradiance) (Fig. 5D), contributing to photoprotection. Numerous studies reported that Cars have a role in thermal dissipation of EEE (Huang et al. 2011; Giorio et al. 2012; Zheng et al. 2012). The higher Car/Chl ratios found in invasive species developed under high-sunlight conditions (at $100 \%$ and $56.2 \%$ irradiance) compared with plants in the shade resulted from both a reduction in the total chlorophyll content and an increase in Car content (Demmig-Adams, 2003). Thus, the high plasticity of Cars may contribute to the invasion success of the invasive at high irradiance.

Photosynthesis is a well-established source of ROS in plants. The photosynthetic electron transport (PET) chain operates in an aerobic environment; thus, regulatory systems are required to minimize ROS production (Foyer and Shigeoka, 2011). Efficient regulation of PET serves to minimize the production of singlet oxygen at PSII as well as the generation of superoxide and $\mathrm{H}_{2} \mathrm{O}_{2}$, which occurs predominantly on the reducing side of PSI. Similar results were also documented in our work (Fig. 6); EEE promotes the TBARS accumulation (except MDA for invasive species) due to the increased LPO. $\mathrm{H}_{2} \mathrm{O}_{2}$ is a potent inhibitor of photosynthesis (Shi et al. 2006) because even at low concentrations it can inhibit $\mathrm{CO}_{2}$ fixation by $50 \%$ due to the oxidation of the thiol-modulated enzymes of the Calvin cycle. Therefore, the balance between ROS production and ROS scavenging 
is delicate and must be strictly controlled. In this study, irradiances increased SOD, CAT, and APX activities, consistent with many previous reports (Jaleel et al. 2009; Gill and Tuteja, 2010). SOD forms the first line of defense to remove $\mathrm{O}_{2}{ }^{--}$via the metal-catalyzed Haber-Weiss-type reaction. The higher SOD level at high irradiance (100\% irradiance) but lower SOD level at low irradiance (Fig. 6D) is likely due to temperature. Peltzer and Polle (2001) revealed that short-term changes in foliar antioxidant systems correlate more with temperature than light, indicating that temperature is an important factor modulating antioxidants. Meanwhile, the increase in CAT activity with increasing irradiance may be related to the photorespiratory detoxification of $\mathrm{H}_{2} \mathrm{O}_{2}$ through the mitochondrial electron transport systems (Huylenbroeck et al. 2000). By contrast, in some pioneer species, CAT activity decreases at high irradiance (Favaretto et al. 2011) because CAT is light-sensitive and suffers from photoinactivation with subsequent degradation in intact leaves. Thus, we postulated that CAT inactivation could also be mediated by photooxidative events initiated through light absorption by chlorophyll. In the ascorbate-glutathione cycle, the first step is the APX-catalyzed reduction of $\mathrm{H}_{2} \mathrm{O}_{2}$ to water, where APX serves as an electron donor (Zheng et al. 2012). An increase in APX activity was observed at high irradiances (Fig. 6E), indicating the important role of APX in removing $\mathrm{H}_{2} \mathrm{O}_{2}$ from the cell. Conversely, plants at low irradiances were less exposed to an overenergization (lowest NPQ) and in turn do not show an enhanced oxidative burst. Indeed, harvested excitation energy is mostly used in photosynthesis. However, Peltzer and Polle (2001) observed that APX activity does not fluctuate according to light exposure in field-grown beech trees.

The above results confirm the importance of antioxidative enzymes and the value of genetically enhanced antioxidants as a mechanism for stabilizing photosynthesis in stress situations. Enhanced antioxidant capacity provides added protection to photosynthesis and illustrates the point that an excess capacity does not exist for ROS destruction. Rather, such findings suggest that the capacity for ROS detoxification is balanced with regard to ROS production. This idea is perhaps surprising given the susceptibility of the photosynthetic processes to oxidative inactivation. However, if one considers that ROS generated in photosynthesis participate in a redox signaling cascade, then the importance of the regulation of both ROS abundance and the lifetime of the ROS signal becomes apparent (Foyer and Shigeoka, 2011). Acclimation to high light is known to involve increases in antioxidants and decreases in light-harvesting antenna size that are likely due to changes in gene 
expression (Rodríguez-López et al. 2014). Moreover, ROS are considered to act as second messengers in the pathways responsible for high-light stress perception and long-distance signal transduction (Szechyńska-Hebda et al. 2010). Consequently, antioxidant systems have evolved in a manner that does not completely remove ROS but allows these signals to persist within the cellular environment.

As part of the redox signaling system, the concentrations of antioxidants and ROS are therefore key elements in understanding the adaptations of invasive plants to new environments and predicting the responses of native species. Recently, a few studies compared native to invasive species in relation to antioxidants and therefore sought to determine a mechanistic link between antioxidant protection and invasion success (Pintó-Marijuan and Munné-Bosch, 2013). A native (Ulex europaeus) and an invasive (Acacia longifolia) species were subjected to salt stress, and antioxidant enzymes were analyzed (Morais, et al. 2012). The results suggest that the invasive coped better with salinity in part due to higher CAT and glutathione reductase that allowed better scavenging of the ROS generated by salt stress. In this study, compared with its native congeners, $A$. formosana exhibited significantly higher SOD and APX at three irradiances and CAT only at $12.5 \%$ irradiance (Fig. 6). With better antioxidant protection, the invasive exhibit an advantage when competing with the natives. On the other hand, high-light acclimation of plants enhances photosynthetic capacity while avoiding the deleterious effects of ROS accumulation under excess light energy (Walters, 2005; Nishiyama et al. 2011). Because the photosynthetic energy utilization in invasive and native species exhibited some differences, it was assumed that higher antioxidant protection would be necessary to compensate for higher light-mediated oxidative stress (Huylenbroeck et al. 2000; Favaretto et al. 2011). However, more studies are needed to better characterize cellular redox homeostasis in other invasive species and compare these processes with that of native species to provide better insights into the mechanistic link between antioxidant protection and invasion success in particular ecosystems.

\section{Conclusion}

In conclusion, invasive $A$. formosana may occupy new habitat successfully through tolerating shading at low irradiance and out-compete native species by improving the light energy utilization via allocating a higher $A_{\max }$, LSP, and Cars to photosynthesis and detected antioxidants when 
irradiance is increased; however, native A. cremastogyne may avoid photoinhibition mainly by dissipating EEE as heat in the form of non-radiative dissipation. Our study is the first to compare the ecophysiological traits of invasive Alnus species and its native congeners, and few studies have compared the plasticity in fitness-related plant traits. Our results indicated that the relationship between the invasiveness and plasticity of specific traits was complex. Plastic responses of plants depend on their intrinsic characteristics as well as the category and range of target environments. A species may exhibit higher plasticity in some traits than another species in a certain set of environments, but this plasticity may not be evident in other traits or for the same traits in a different environment (Palacio-López and Gianoli, 2011). Thus, further comparative studies on more invasive and native congeners at a wide range of irradiances are necessary to understand the generality of the patterns and fully determine the competitive advantages provided by these ecophysiological features.

\section{Acknowledgments}

This work was partially sponsored by the National Natural Science Foundation in China (31570700) and the Emerging Talents Scheme of Sichuan Province in China (00370501). Authors' roles: Study design and conduct: SLL and MDM. Performed the experiments and analyzed the data: SLL and RJY. Contributed equipment/materials: RJY and BR. Wrote the paper: SLL. Approving final version: all authors. SLL takes responsibility for the integrity of the data analysis. The authors thank MHW for technical assistance.

\section{References}

Allred, B.W., Fuhlendorf, S.D., Monaco, T.A., and Will, R.E., 2010. Morphological and physiological traits in the success of the invasive plant Lespedeza cuneata. Biol. Invasions 12, 739-749. doi: 10.1007/s10530-009-9476-6.

Araújo, W.L., Fernie, A.R., and Nunes-Nesi, A., 2011. Control of stomatal aperture. A renaissance of the old guard. Plant Signal. Behav. 6, 1305-1311. doi: 10.4161/psb.6.9.16425.

Beauchamp, C., and Fridovich, I., 1971. Superoxide dismutase: improved assays and an assay applicable to acrylamide gels. Anal. Biochem. 44, 276-286. doi: 10.1016/0003-2697(71)90370-8.

Cakmak, I., and Marschner, H., 1992. Magnesium deficiency and high light intensity enhance activities of superoxide dismutase, ascorbate peroxidase and glutathione reductase in bean leaves. Plant Physiol. 98, 1222-1227. doi: 10.1104/pp.98.4.1222.

Campos, H., Trejo, C, Peña-Valdivia, C.B., García-Nava, R., Conde-Martínez, F.V., and Cruz-Ortega, M.R., 2014. Photosynthetic acclimation to drought stress in Agave salmiana Otto ex Salm-Dyck seedlings is largely dependent on thermal dissipation and enhanced electron flux to photosystem I. Photosynth. Res. 122: 23-39 doi: 10.1007/s11120-014-0008-6.

Chazdon, R.L., and Pearcy, R.W., 1991. The importance of sunflecks for forests understory plants. BioScience 41,760-766. doi: 10.2307/1311725. 
Daehler, C.C., 2003. Performance comparisons of co-occurring native and alien invasive plants: implications for conservation and restoration. Annu. Rev. Ecol. Evol. Syst. 34, 183-211. doi: 10.1146/annurev.ecolsys.34.011802.132403.

Dai, Y.J., Shen, Z.G., Liu, Y., Wang, L.L., Hannaway, D., and Lu, H.F., 2009. Effects of shade treatments on the photosynthetic capacity, chlorophyll fluorescence, and chlorophyll content of Tetrastigma hemsleyanum Diels et Gilg. Environ. Exp. Bot. 65, 177-182. doi:10.1016/j.envexpbot.2008.12.008.

Demmig-Adams, B., 2003. Linking the xanthophyll cycle with thermal energy dissipation. Photosynth. Res. 76, 73-80. doi: 10.1023/A:1024902927403.

Fan, S., Liu, C., Yu, D., and Xie, D., 2013. Differences in leaf nitrogen content, photosynthesis, and resource-use efficiency between Eichhornia crassipes and a native plant Monochoria vaginalis in response to altered sediment nutrient levels. Hydrobiologia 711,129-137. doi: 10.1007/s10750-013-1471-3.

Farquhar, G.D., and Sharkey, T.D., 1982. Stomatal conductance and photosynthesis. Ann. Rev. Plant Physiol. 33, 317-345. doi: 10.1146/annurev.pp.33.060182.001533.

Favaretto, V.F., Martinez, C.A., Soriani, H.H., and Furriel, R.P.M., 2011. Differential responses of antioxidant enzymes in pioneer and late-successional tropical tree species grown under sun and shade conditions. Environ. Exp. Bot. 70, 20-28. doi: 10.1016/j.envexpbot.2010.06.003.

Feng, Y.L., 2008. Photosynthesis, nitrogen allocation and specific leaf area in invasive Eupatorium adenophorum and native Eupatorium japonicum grown at different irradiances. Physiol. Plant. 133, 318-326. doi: 10.1111/j.1399-3054.2008.01072.x.

Feng, Y.L., Auge, H., and Ebeling, S.K., 2007. Invasive Buddleja davidii allocates more nitrogen to its 6 photosynthetic machinery than five native woody species. Oecologia 153, 501-510. doi: 10.1007/s00442-007-0759-2.

Foyer, C.H., and Shigeoka, S., 2011. Understanding oxidative stress and antioxidant functions to enhance photosynthesis. Plant Physiol. 155, 93-100. doi: 10.1104/pp.110.166181.

Gill, S.S., and Tuteja, N., 2010. Reactive oxygen species and antioxidant machinery in abiotic stress tolerance in crop plants. Plant Physiol. Biochem. 48, 909-930. doi: 10.1016/j.plaphy.2010.08.016.

Giorio, P., Giorio, G., Guadagno, C.G., Cellini, F., Stigliani, A., and D'Ambrosio, G., 2012. Carotenoid content, leaf gas-exchange, and non-photochemical quenching in transgenic tomato overexpressing the $\beta$-carotene hydroxylase 2 gene (CrtR-b2). Environ. Exp. Bot. 75, 1-8. doi:10.1016/j.envexpbot.2011.08.009.

Grotkopp, E., and Rejmánek, M., 2007. High seedling relative growth rate and specific leaf area are traits of invasive species: phylogenetically independent contrasts of woody angiosperms. Am. J. Bot. 94, 526-532. doi: 10.3732/ajb.94.4.526.

Heath, R.L., and Packer, L., 1968. Photoperoxidation in isolated chloroplasts I kinetics and stoichiometry of fatty acid peroxidation. Arch. Biochem. Biophy. 125, 189-198. doi: 10.1016/0003-9861(68)90654-1.

Huang, D., Wu, L., Chen, J.R., and Dong, L., 2011. Morphological plasticity, photosynthesis and chlorophyll fluorescence of Athyrium pachyphlebium at different shade levels. Photosynthetica 49, 611-618. doi: 10.1007/s11099-011-0076-1.

Huang, W., Zhang, J.L., Zhang, S.B., and Hua, H., 2014. Evidence for the regulation of leaf movement by photosystem II activity. Environ. Exp. Bot. 107,167-172. doi:10.1016/j.envexpbot.2014.06.010.

Huylenbroeck, J.M., Piqueras, V.A., and Debergh, P.C., 2000. The evolution of photosynthetic capacity and the antioxidant enzymatic system during acclimatization of micropropagated Calathea plants. Plant Sci. 155, 59-66. doi: 10.1016/S0168-9452(00)00201-6.

Hyldgaard, B., and Brix, H., 2012. Intraspecies differences in phenotypic plasticity: Invasive versus non-invasive populations of Ceratophyllum demersum. Aquat. Bot. 97, 49- 56. doi: 10.1016/j.aquabot.2011.11.004.

Jaleel, C.A., Riadh, K., Gopi, R., Manivannan, P., Inès, J., AlJuburi, H.J., Zhao, C.X., Shao, H.B., and Panneerselvam, R., 2009. Antioxidant defense responses: physiological plasticity in higher plants under abiotic constraints. Physiol. Plant. 31, 427-436. doi: 10.1007/s11738-009-0275-6.

Jones, H.G., 1985. Partitioning stomatal and non-stomatal limitations to photosynthesis. Plant Cell Environ. 8, 95-104. doi: 10.1111/j.1365-3040.1985.tb01227.x. 
Krause, G.H., Koroleva, O.Y., Dalling, J.W., and Winter, K., 2001. Acclimation of tropical tree seedlings to excessive light in simulated tree-fall gaps. Plant Cell Environ. 24: 1345-1352. doi: 10.1046/j.0016-8025.2001.00786.x.

Lai, Y.C., Chen, C.K., Lin, W.W., and Lee, S., 2012. A comprehensive investigation of anti-inflammatory diarylheptanoids from the leaves of Alnus formosana. Photochemistry 73, 84-94. doi: 10.1016/j.phytochem.2011.02.008.

Li, Y.P., Feng, L.Y., and Barclay, G., 2012. No evidence for evolutionarily decreased tolerance and increased fitness in invasive Chromolaena odorata: implications for invasiveness and biological control. Plant Ecol. 213, 1157-1166. doi: 10.1007/s11258-012-0073-X.

Liao, Z.Y., Zhang, R., Barclay, G.F., and Feng, Y.L., 2013. Differences in competitive ability between plants from nonnative and native populations of a tropical invader relates to adaptive responses in abiotic and biotic environments. PLoS ONE 8: e71767. doi:10.1371/journal.pone.0071767.

Lichtenthaler, H.K., 1987. Chlorophylls and carotenoids: pigments of photosynthetic biomembranes. Methods Enzymol. 148, 350-382. doi:10.1016/0076-6879(87)48036-1.

Nakano, Y., and Asada, K., 1981. Hydrogen peroxide is scavenged by ascorbate-specific peroxidase in spinach chloroplasts. Plant Cell Physiol. 22, 867-880.

Nishiyama, Y., Allakhverdiev, S.I., and Murata, N., 2011. Protein synthesis is the primary target of reactive oxygen species in the photoinhibition of photosystem II. Physiol. Plant. 142, 35-46. doi: 10.1111/j.1399-3054.2011.01457.x.

Maxwell, K., and Johnson, G.N., 2000. Chlorophyll fluorescence-a practical guide. J. Exp. Bot. 51, 659-668. doi: 10.1093/jexbot/51.345.659.

Morais, M.C., Panuccio, M.R., Muscolo, A., and Freitas, H., 2012. Salt tolerance traits increase the invasive success of Acacia longifolia in Portuguese coastal dunes. Plant Physiol. Biochem. 55, 60-65. doi:10.1016/j.plaphy.2012.03.013.

O'Carrigana, A., Hindeb, E., Lua, N., Xua, X.Q., Duanc,H., Huangc, G., Maka, M., Bellotti, B., and Chena, Z.H., 2014. Effects of light irradiance on stomatal regulation and growth of tomato. Environ. Exp. Bot. 98, 65-73. doi: 10.1016/j.envexpbot.2013.10.007.

Palacio-López, K., and Gianoli, E., 2011. Invasive plants do not display greater phenotypic plasticity than their native or non-invasive counterparts: a meta-analysis. Oikos 120, 1393-1401. doi: 10.1111/j.1600-0706.2010.19114.x.

Papageorgiou, G.C., and Govindjee, 2011. Photosystem II fluorescence: Slow changes-Scaling from the past. J. Photoch. Photobio. B104, 258-270. doi: 10.1016/j.jphotobiol.2011.03.008.

Patterson, B.D., Mackac, E.A., and Ferguson, I.B., 1984. Estimation of hydrogen peroxide in plant extracts using titanium (IV). Anal. Biochem. 139, 487-492. doi: 10.1016/0003-2697(84)90039-3.

Peltzer, D., and Polle, A., 2001. Diurnal fluctuations of antioxidative systems in leaves of field-grown beech trees (Fagus sylvatica): response to light and temperature. Physiol. Plant. 111, 158-164. doi: 10.1034/j.1399-3054.2001.1110205.x.

Pintó-Marijuan, M., and Munné-Bosch, S., 2013. Ecophysiology of invasive plants: osmotic adjustment and antioxidants. Trends Plant Sci.18, 660-666. doi: 10.1016/j.tplants.2013.08.006.

Shi, Q., Zhu, Z., Xu, M., Qian, Q., and Yu, J., 2006. Effect of excess manganese on the antioxidant system in Cucumis sativus L. under two light intensities. Environ. Exp. Bot. 58, 197-205. doi: 10.1016/j.envexpbot.2005.08.005.

Szechyńska-Hebda, M., Kruk, J., Gorecka, M., Karpinska, B., and Karpinski, S., 2010. Evidence for light wavelength-specific photo electrophysiological signaling and memory of excess light episodes in Arabidopsis. Plant Cell 22, 2201-2218. doi: 10.1105/tpc.109.069302.

Rodríguez-López, N.F., Martins, S.C.V., Cavatte, P.C., Silva, P.E.M., Morais, L.E., Pereira, L.F., Reis, J.V., Ávila, R.T., Godoy, A.G., Lavinski, A.O., and DaMatta, F.M., 2014. Morphological and physiological acclimations of coffee seedlings to growth over a range of fixed or changing light supplies. Environ. Exp. Bot. 102, 1-10. doi: 10.1016/j.envexpbot.2014.01.008. 
Walters, R.G., 2005. Towards an understanding of photosynthetic acclimation. J. Exp. Bot. 56, $435-447$. doi:10.1093/jxb/eri060.

Yamashita, N., Ishida, A., Kushima, H., and Tanaka, N., 2000. Acclimation to sudden increase in light favoring an invasive over native trees in subtropical islands, Japan. Oecologia 125, 412-419. doi: $10.1007 / \mathrm{s} 004420000475$.

Ye, Z., 2007. A new model for relationship between irradiance and the rate of photosynthesis in Oryza sativa. Photosynthetica 45, 637-640. doi: 10.1007/s11099-007-0110-5.

Zwolinski, J.B., Donald, D.G.M., Gerischer, G.F.R., and Wyk, W.J., 1992. Characteristics and wood properties of Alnus formosana (Burk.) Makino successfully introduced into South Africa. S. Afr. Forest. J. 163, 31-35. doi: 10.1080/00382167.1992.9629365.

Zheng, Y.L., Feng, Y.L., Lei, Y.B., and Liao, Z.Y., 2012. Comparisons of plastic responses to irradiance and physiological traits by invasive Eupatorium adenophorum and its native congeners. J. Plant. Physiol. 169, 884-891. doi: 10.1016/j.jplph.2012.02.011. 


\section{Figure captions}

Fig. 1. Response of net photosynthetic rate $\left(A_{\mathrm{n}}\right)$ to incident photosynthetic photon flux density (PPFD) for leaves of invasive A. formosana (A) and native A. cremastogyne (B) exposed to $12.5 \%$ (Triangles), 56.2\% (Circles) and 100\% (Squares) irradiances. Data are the means of five independent experiments with SE shown by vertical bars.

Fig. 2. Apparent quantum yield (AQY, A), light saturation point (LSP, B), light-saturated photosynthetic rate $\left(A_{\max }, \mathrm{C}\right)$ and light compensation point (LCP, D) in the seedlings of invasive $A$. formosana (black bars) and native A. cremastogyne (red bars) grown at $12.5 \%, 56.2 \%$ and $100 \%$ irradiances. Different capital and small letters indicate significant differences $(P<0.05)$ among species at the same irradiance and among irradiances for the same species, respectively. ${ }^{*}, P<0.05$; **, $P<0.01$; ns, $P>0.05$. Data are the means of five independent experiments with SE shown by vertical bars.

Fig. 3. Maximum photochemical efficiency of PSII $\left(F_{\mathrm{v}} / F_{\mathrm{m}}\right)$ and non-photochemical quenching (NPQ) in the seedlings of invasive A. formosana (A and C) and native A. cremastogyne (B and D) grown at $12.5 \%, 56.2 \%$ and $100 \%$ irradiances. Data are the means of six independent experiments with SE shown by vertical bars.

Fig. 4. Net photosynthetic rate $\left(A_{\mathrm{n}}, \mathrm{A}\right)$, transpiration rate $\left(T_{\mathrm{r}}, \mathrm{B}\right)$, stomatal conductance $\left(G_{\mathrm{s}}, \mathrm{C}\right)$, intercellular $\mathrm{CO}_{2}$ concentration $\left(C_{\mathrm{i}}, \mathrm{D}\right)$, light use efficiency (LUE, E) and stomatal limitation $\left(L_{\mathrm{s}}, \mathrm{F}\right)$ in the seedlings of invasive $A$. formosana (black bars) and native $A$. cremastogyne (red bars) grown 
at $12.5 \%, 56.2 \%$ and $100 \%$ irradiances. Data are the means of five independent experiments with SE shown by vertical bars. Other details are the same as in Fig. 2.

Fig. 5. Chlorophyll $a$ (Chla, A), chlorophyll $b$ (Chlb, B), total chlorophyll (Chl, C), chlorophyll $a$ chlorophyll $b$ (Chla/b, D), carotenoid (Car, E), and carotenoid/total chlorophyll (Car/Chl, F) in the seedlings of invasive A. formosana (black bars) and native A. cremastogyne (red bars) grown at $12.5 \%, 56.2 \%$ and $100 \%$ irradiances. Data are the means of five independent experiments with SE shown by vertical bars. Other details are the same as in Fig. 2.

Fig. 6. Hydrogen peroxide $\left(\mathrm{H}_{2} \mathrm{O}_{2}, A\right)$, malondialdehyde (MDA, B), catalase (CAT, C), catalase (SOD, D) and ascorbate peroxidase (APX, E) in the seedlings of invasive A. formosana (black bars) and native A. cremastogyne (red bars) grown at $12.5 \%, 56.2 \%$ and $100 \%$ irradiances. Data are the means of 4-6 independent experiments with SE shown by vertical bars $\left(n=4\right.$ for $\mathrm{H}_{2} \mathrm{O}_{2}$ and MDA; $n$ $=5$ for others). Other details are the same as in Fig. 2. 
Fig. 1
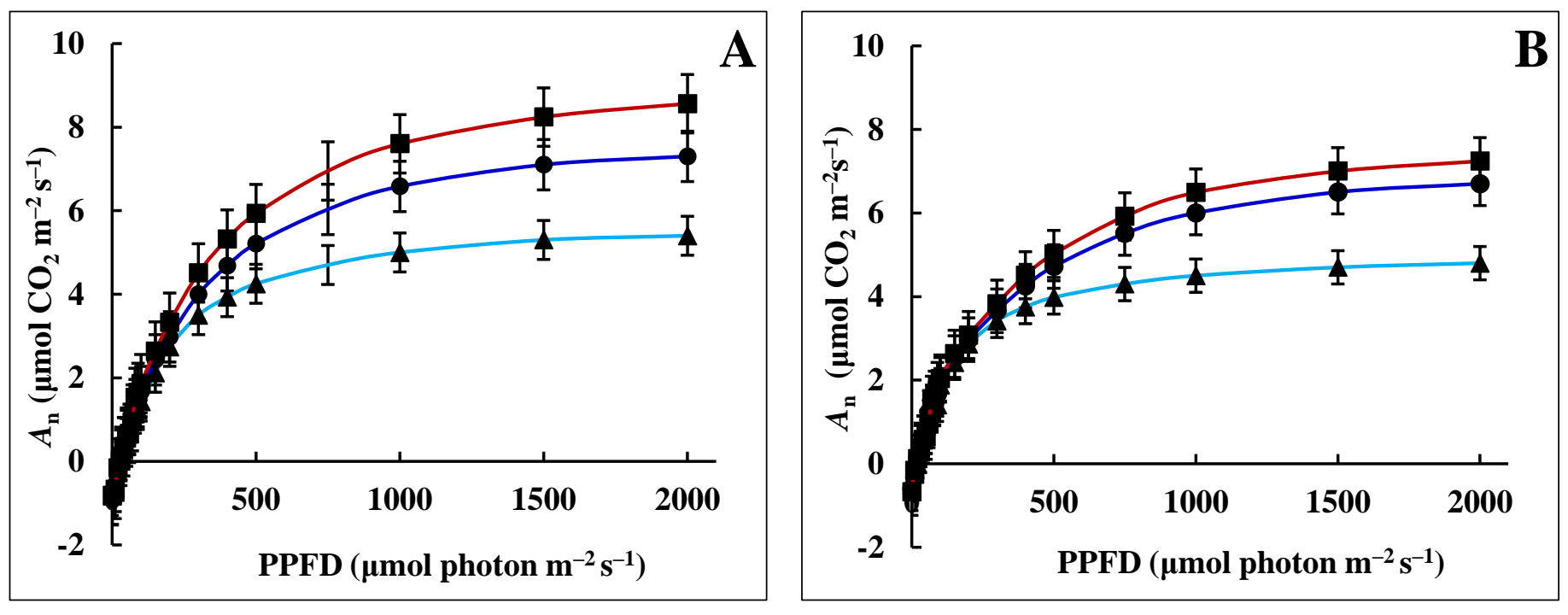
Fig. 2
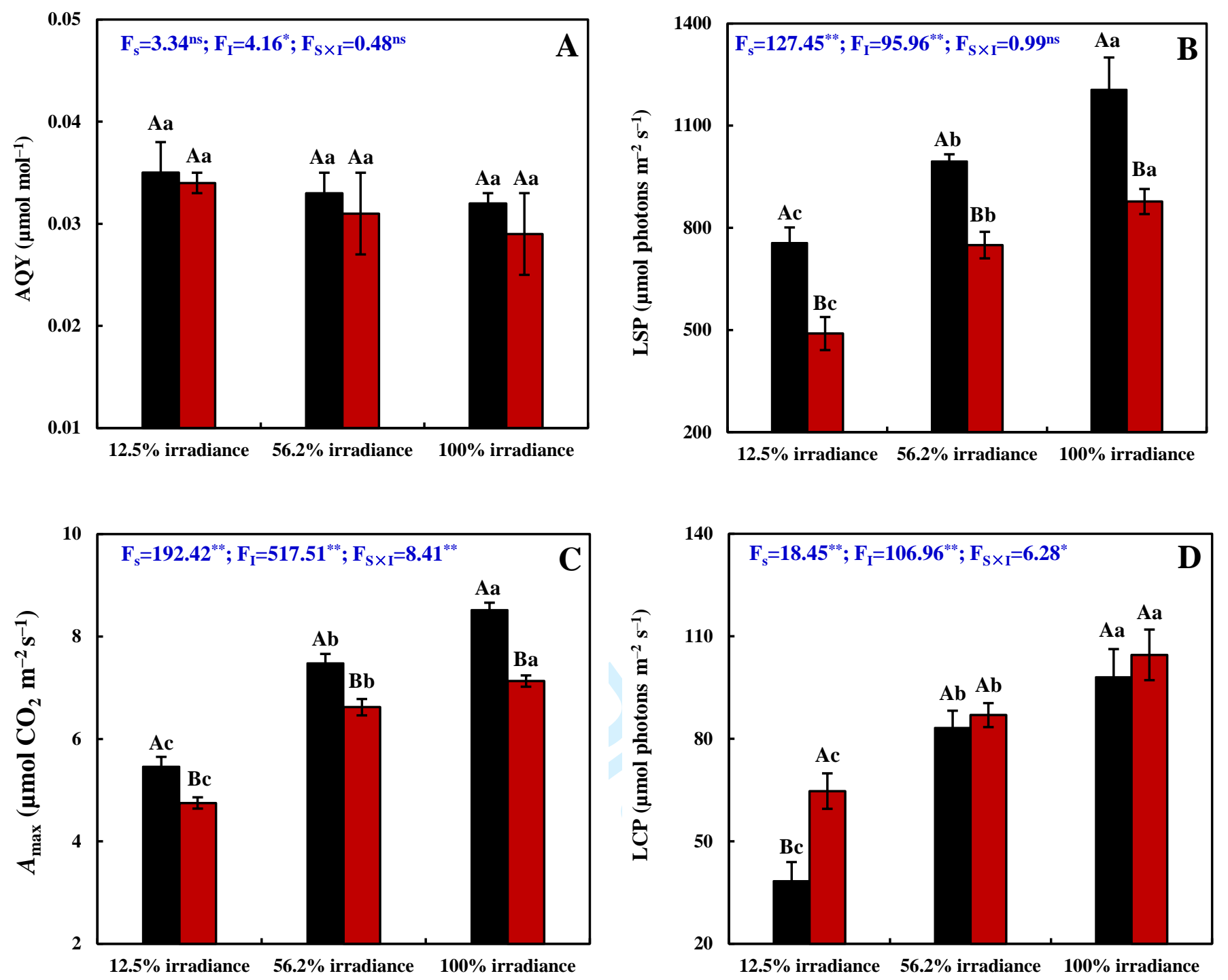
Fig. 3
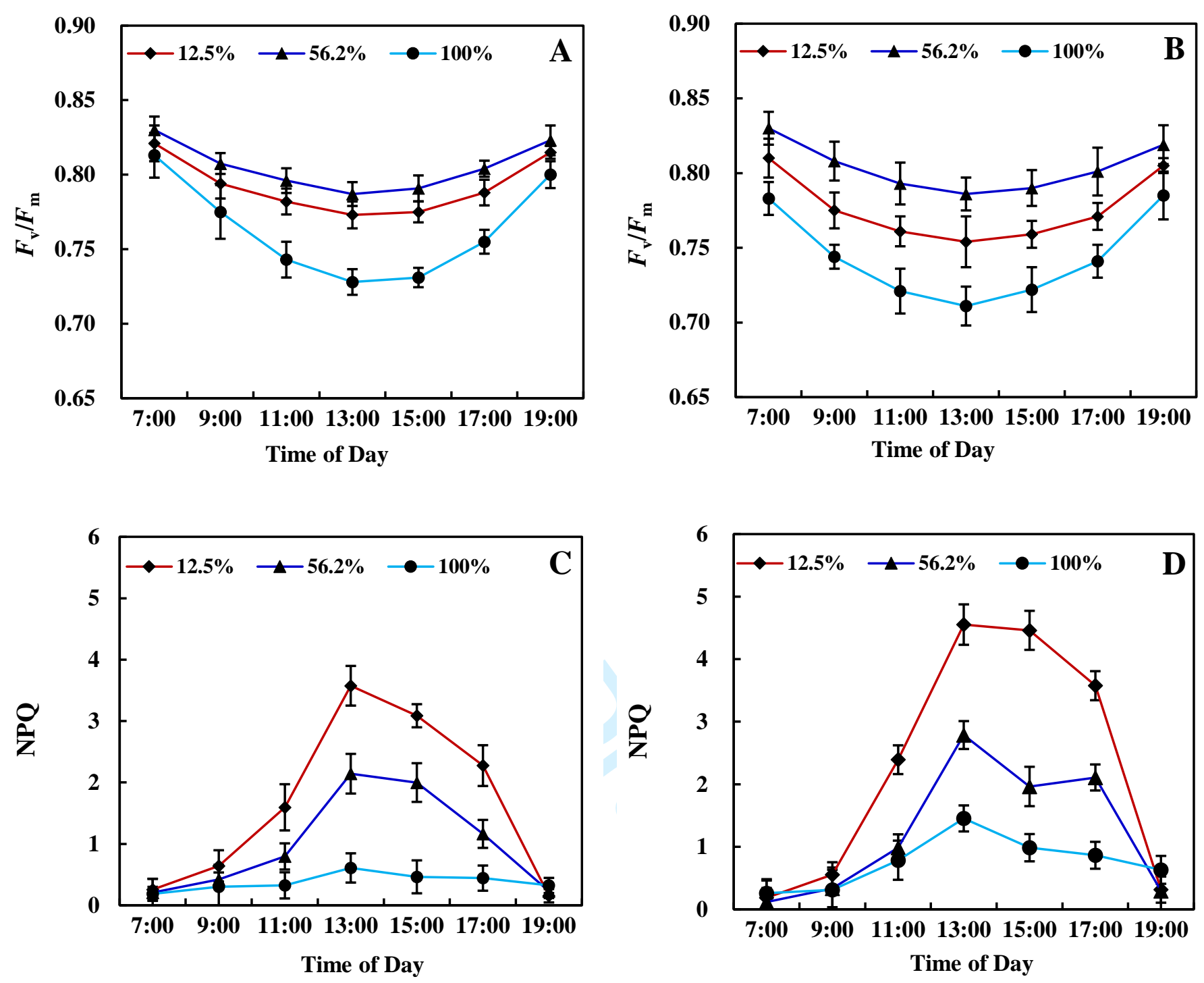
Fig. 4
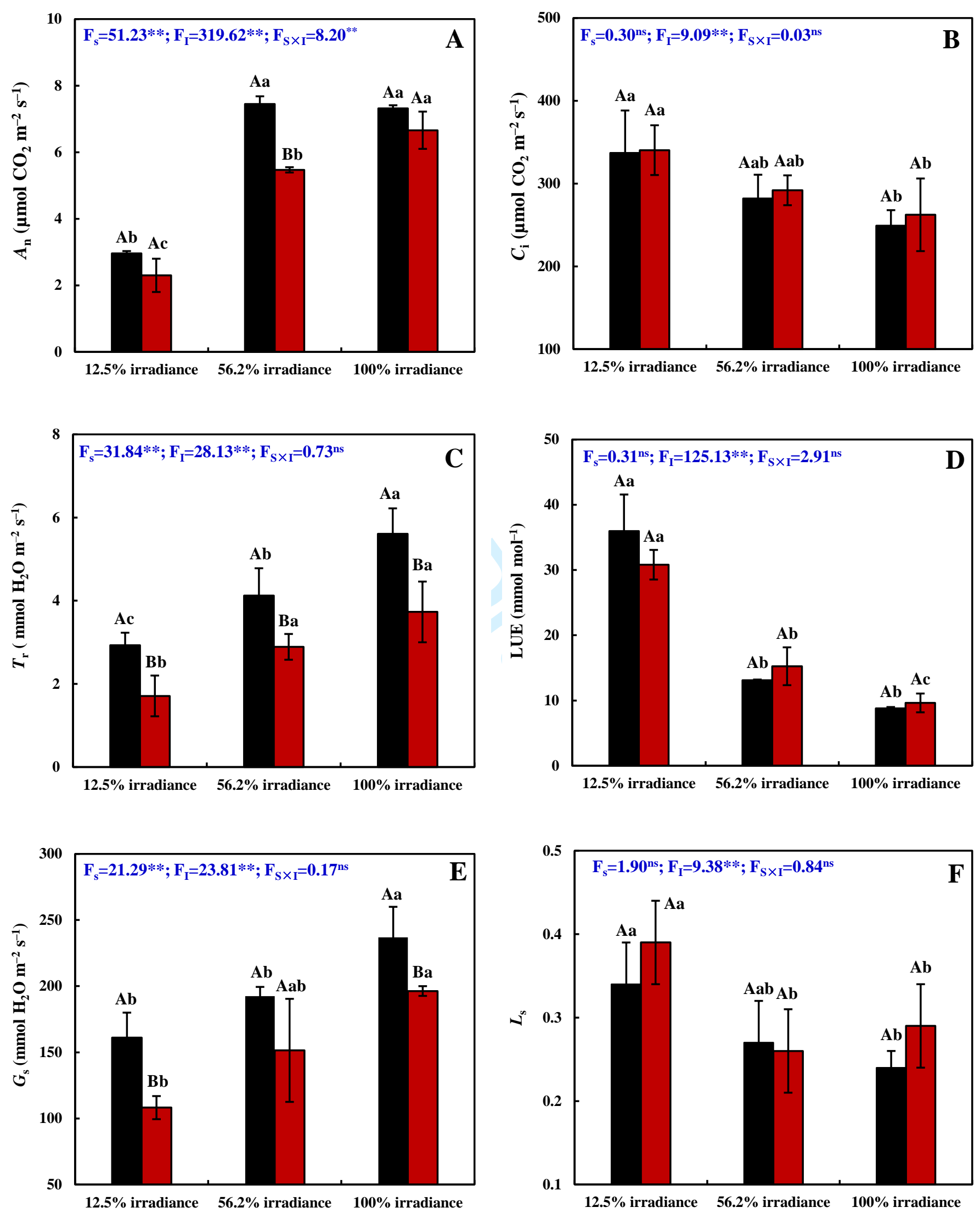


\section{Fig. 5}
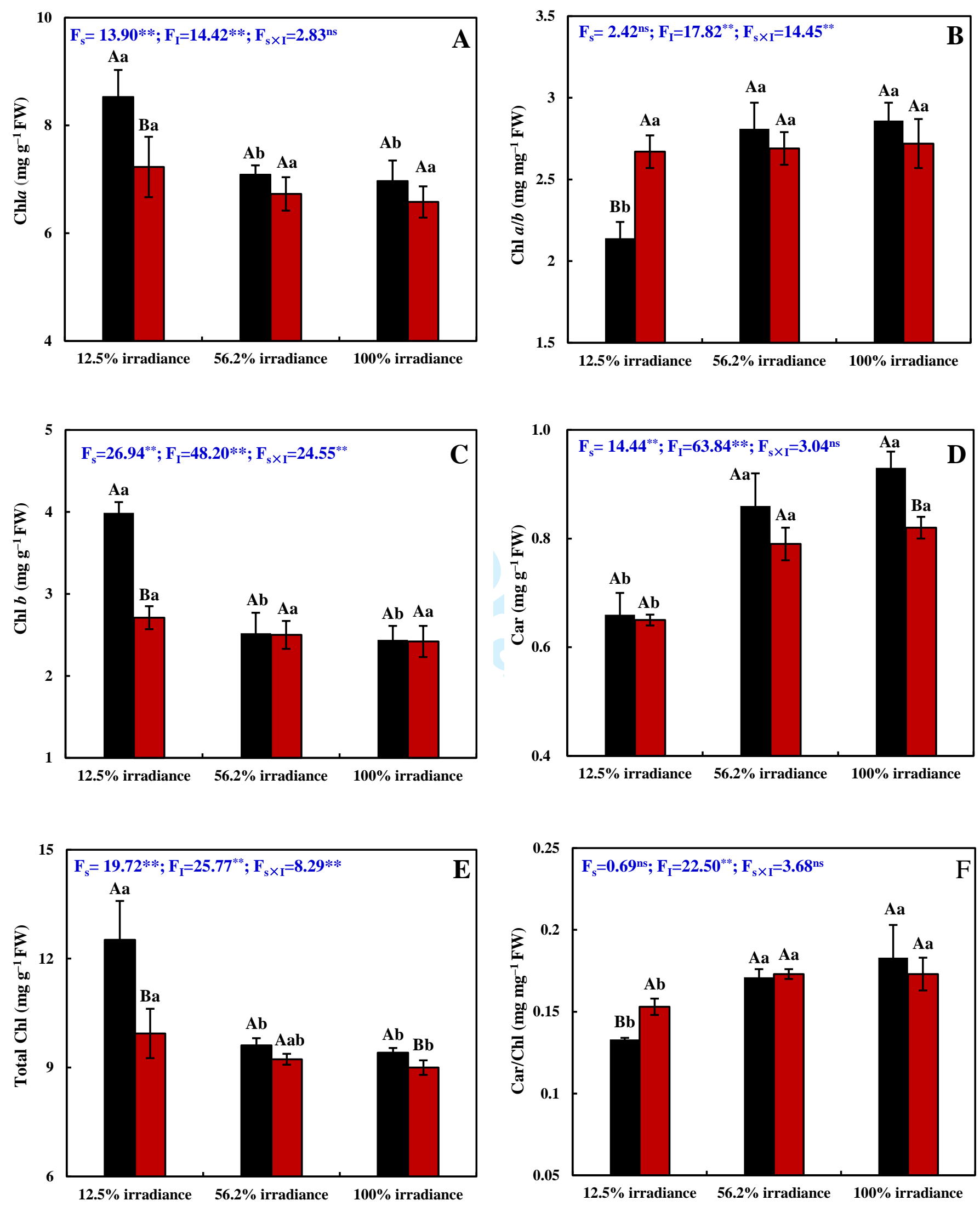
Fig. 6
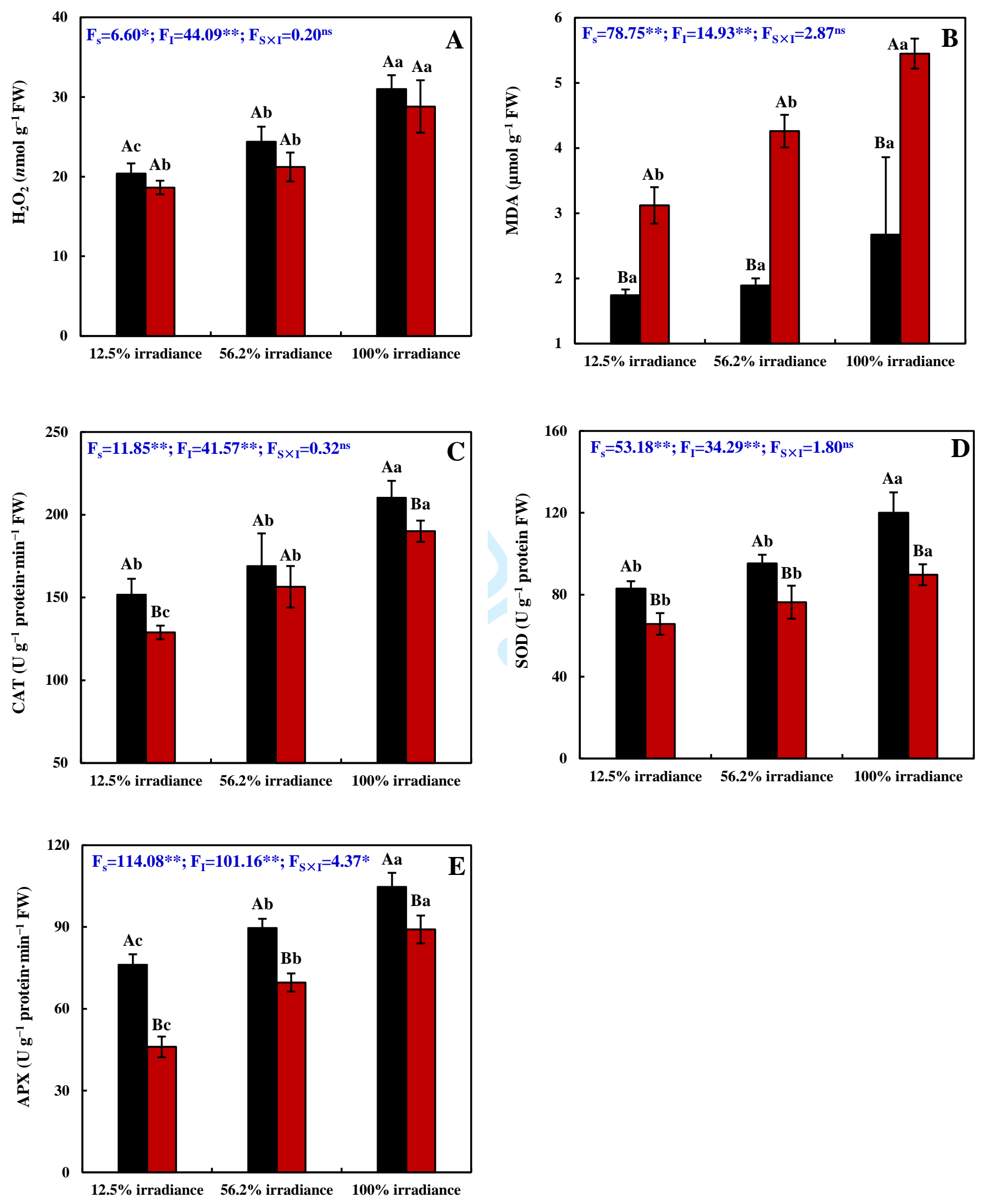